University of Nebraska - Lincoln

DigitalCommons@University of Nebraska - Lincoln

Faculty Publications from the Harold W. Manter Laboratory of Parasitology

$2-1-2004$

\title{
Mapping the Presence of Wolbachia pipientis on the Phylogeny of Filarial Nematodes: Evidence for Symbiont Loss During Evolution
}

\author{
Maurizio Casiraghi \\ Università degli Studi di Milano, maurizio.casiraghi@unimib.it \\ Odile Bain \\ Muséum National d'Histoire Naturelle et Ecole Pratique des Hautes Etudes, Paris, bain@cimrs1.mnhn.fr \\ Ricardo Guerrero \\ Universidad Central de Venezuela \\ Coralie Martin \\ Muséum National d'Histoire Naturelle et Ecole Pratique des Hautes Etudes \\ Vanessa Pocacqua \\ Università degli Studi di Milano \\ See next page for additional authors
}

Follow this and additional works at: https://digitalcommons.unl.edu/parasitologyfacpubs

Part of the Parasitology Commons

Casiraghi, Maurizio; Bain, Odile; Guerrero, Ricardo; Martin, Coralie; Pocacqua, Vanessa; Gardner, Scott Lyell; Francheschi, Alberto; and Bandi, Claudio, "Mapping the Presence of Wolbachia pipientis on the Phylogeny of Filarial Nematodes: Evidence for Symbiont Loss During Evolution" (2004). Faculty Publications from the Harold W. Manter Laboratory of Parasitology. 5.

https://digitalcommons.unl.edu/parasitologyfacpubs/5

This Article is brought to you for free and open access by the Parasitology, Harold W. Manter Laboratory of at DigitalCommons@University of Nebraska - Lincoln. It has been accepted for inclusion in Faculty Publications from the Harold W. Manter Laboratory of Parasitology by an authorized administrator of DigitalCommons@University of Nebraska - Lincoln. 


\section{Authors}

Maurizio Casiraghi, Odile Bain, Ricardo Guerrero, Coralie Martin, Vanessa Pocacqua, Scott Lyell Gardner, Alberto Francheschi, and Claudio Bandi 
International Journal for Parasitology, Vol. 34, Issue 2, February 2004, pp. 191-203.

Annual Scientific Meeting of the Australian Society for Parasitology, Darwin, Carlton Hotel, The Esplande, 2003. Highlights.

http://www.sciencedirect.com/science/journal/00207519 doi:10.1016/j.ijpara.2003.10.004

Copyright (C 2003 Australian Society for Parasitology Inc. Published by Elsevier Science Ltd.

\title{
Mapping the presence of Wolbachia pipientis on the phylogeny of filarial nematodes: Evidence for symbiont loss during evolution
}

\author{
Maurizio Casiraghi a , Odile Bain ${ }^{\text {b }}$, Ricardo Guerrero c, Coralie Martin b, 1 , \\ Vanessa Pocacqua a , Scott L. Gardner d, Alberto Franceschi ${ }^{a}$ and Claudio Bandi a \\ a Dipartimento di Patologia Animale, Igiene e Sanità Pubblica Veterinaria, \\ Sezione di Patologia Animale e Parassitologia, Università degli Studi di Milano, via Celoria 10, 20133, Milano, Italy \\ b Parasitologie comparée et Modèles expérimentaux, associée à l'INSERM (U567), Ecologie et gestion de la Biodiversité, \\ Muséum National d'Histoire Naturelle et Ecole Pratique des Hautes Etudes, 61 rue Buffon, 75231, Paris Cedex O5, France \\ c Instituto de Zoologia Tropical, Faculdad de Ciencias, Universidad Central de Venezuela, PO Box 47058, 1041A, Caracas, Venezuela \\ d Harold W. Manter Laboratory of Parasitology, University of Nebraska-Lincoln, W-529 Nebraska Hall, Lincoln, NE 68588-0514, USA \\ ${ }^{1}$ Present address: Leukocyte Biology Section, Division of Biomedical Sciences, Faculty of Medicine, \\ Imperial College of Science, Technology and Medicine, London, UK. \\ Corresponding author: Claudio Bandi, claudio.bandi@unimi.it.
}

Submitted July 21, 2003; revised September 29, 2003; accepted October 9, 2003. Published online February 18, 2004.

Nucleotide sequence data reported in this paper are available in the EMBL Data Library database under the accession numbers: AJ544831-AJ544858; AJ544867-AJ544882; AJ548798-J548802.

\begin{abstract}
Wolbachia pipientis is a bacterial endosymbiont associated with arthropods and filarial nematodes. In filarial nematodes, W. pipientis has been shown to play an important role in the biology of the host and in the immuno-pathology of filariasis. Several species of filariae, including the most important parasites of humans and animals (e.g. Onchocerca volvulus, Wuchereria bancrofti and Dirofilaria immitis) have been shown to harbor these bacteria. Other filarial species, including an important rodent species (Acanthocheilonema viteae), which has been used as a model for the study of filariasis, do not appear to harbor these symbionts. There are still several open questions about the distribution of $W$. pipientis in filarial nematodes. Firstly the number of species examined is still limited. Secondly, it is not clear whether the absence of $W$. pipientis in negative species could represent an ancestral characteristic or the result of a secondary loss. Thirdly, several aspects of the phylogeny of filarial nematodes are still unclear and it is thus difficult to overlay the presence/absence of $W$. pipientis on a tree representing filarial evolution. Here we present the results of a PCR screening for $W$. pipientis in 16 species of filariae and related nematodes, representing different families/subfamilies. Evidence for the presence of $W$. pipientis is reported for five species examined for the first time (representing the genera $L i$ tomosoides, Litomosa and Dipetalonema); original results on the absence of this bacterium are reported for nine species; for the remaining two species, we have confirmed the absence of $W$. pipientis recently reported by other authors. In the positive species, the infecting $W$. pipientis bacteria have been identified through $16 S$ rDNA gene sequence analysis. In addition to the screening for $W$. pipientis in 16 species, we have generated phylogenetic reconstructions based on mitochondrial gene sequences (12S rDNA; $\mathrm{COI}$ ), including a total of 28 filarial species and related spirurid nematodes. The mapping of the presence/absence of $W$. pipientis on the trees generated indicates that these bacteria have possibly been lost during evolution along some lineages of filarial nematodes.
\end{abstract}

Keywords: Filarial nematodes; Wolbachia pipientis; Phylogeny; Symbiosis; Thelazia

\section{Introduction}

Intracellular bacteria belonging to the species Wolbachia pipientis Hertig 1936 have attracted a great deal of attention (Knight, 2001; Zimmer, 2001 and Hurst and Randerson, 2002). These bacteria are present in arthropods and filarial nematodes (Werren, 1997). In arthropods W. pipientis generally induces alterations in host reproduction (Werren, 1997; Stouthamer et al., 1999 and Bandi et al., 2001). In filarial nematodes there is convincing evidence that these bacteria are required for the development and reproduction of their hosts (Genchi et al., 1998; Bandi et 
al., 1999; Hoerauf et al., 1999; McCall et al., 1999; Hoerauf et al., 2000 and Casiraghi et al., 2002).

In filarial nematodes, PCR amplification and sequencing have shown that Wuchereria bancrofti, Litomosoides sigmodontis, Mansonella ozzardi and all the species examined in the genera Dirofilaria, Onchocerca and Brugia harbor W. pipientis (Sironi et al., 1995; Bandi et al., 1998 and Casiraghi et al., 2001a). In positive species, all the specimens examined have been shown to be infected. $W$. pipientis infection thus appears at fixation in these species. A rodent filaria, Acanthocheilonema viteae (belonging to the so-called Dipetalonema sensu lato lineage; Bain et al., 1982), consistently appeared PCR negative for $W$. pipientis in independent studies (e.g. see Bandi et al., 1998 and Hoerauf et al., 1999; for tables listing filarial species positive and negative for $W$. pipientis, see Taylor and Hoerauf, 1999 and Bandi et al., 2001). Recent studies have provided evidence for the absence of W. pipientis in Loa loa and Setaria equina (Chirgwin et al., 2002; Büttner et al., 2003 and Grobusch et al., 2003). Furthermore, microfilariae of Mansonella perstans have been shown to be negative for $W$. pipientis through PCR (Grobusch et al., 2003). In addition to the data generated through PCR and sequencing, electron microscopy and immunohistochemical examinations have contributed to the above picture of the presence/absence of $W$. pipientis in filarial species (e.g. Kozek, 1977 and Henkle-Dührsen et al., 1998). These two approaches have not revealed the presence of $W$. pipientis in Onchocerca flexuosa, but representatives of this species have not yet been examined by PCR (Plenge-Bönig et al., 1995 and HenkleDührsen et al., 1998). Assuming the monophyly of the Onchocerca group, the absence of $W$. pipientis in O. flexuosa could be interpreted as a secondary loss of bacteria in the phylogenetic lineage leading to this species.

There are still several open questions about the distribution of $W$. pipientis in filarial nematodes. Firstly, the number of species examined is still limited. In particular no representatives from some important branches of filarial evolution, such as the family Filariidae and the subfamily Waltonellinae in the Onchocercidae, have thus far been screened for $W$. pipientis through PCR, or for intracellular bacteria through other methods. In addition, in the subfamily Setariinae of the family Onchocercidae only one species has thus far been examined (for a schematic representation of the families and subfamilies mentioned in this study for the superfamily Filarioidea, see Figure 4). Secondly, it is not clear whether the absence of $W$. pipientis in $A$. viteae could represent an ancestral characteristic or the result of a secondary loss. It should be emphasised that $A$. viteae is an important laboratory model, and that all the specimens thus far examined in this species derive from the same strain (collected in Iran from Meriones libycus, see Balthazard et al., 1953). Loss of $W$. pipientis could thus have occurred during laboratory maintenance of $A$. viteae, or could represent a characteristic of this species, not shared by congeneric species. Another genus which includes an important laboratory model is Litomosoides, and only $L$. sigmodontis has been examined for this genus. Thirdly, several aspects of the phylogeny of filarial nematodes are still unclear. Branching order is indeed unresolved in various groups; the positioning of several species is also unclear. It is thus difficult to map the presence/absence of $W$. pipientis on the phylogenetic tree of filarial nematodes, and it is consequently impossible to infer whether the absence of $W$. pipientis in a given species is ancestral (i.e. the bacterium was never present in the phylogenetic line) or derived (i.e. ancestors of the current negative species once harbored $W$. pipientis).

The third point raised above is particularly critical. A phylogenetic scenario of filarial nematodes has been proposed based on morphological characters (Anderson and Bain, 1976; Bain, 1981; Chabaud and Bain, 1994 and Bain, 2002). However, the likelihood of convergence of morphological characters among lineages could weaken some aspects of the proposed evolutionary scenario. Analyses based on molecular characters other than morphological ones are needed in the study of filarial phylogeny to evaluate the previous findings. In addition, while a huge amount of sequence data is available for pathogenic and model filarial parasites (Blaxter et al., 2002), for whole groups of filariae and for several species DNA/protein sequences are not available at all.

In the present study, 16 species of spirurid nematodes were screened for the presence of $W$. pipientis. We examined specimens representing the main lineages of the Filarioidea superfamily, including one representative of the family Filariidae (supposed to be primitive within the Filarioidea), and 13 in the family Onchocercidae, from a wide range of hosts (Table 1). In the Dipetalonema lineage, we included a species of Acanthocheilonema from a carnivore, and a species of Dipetalonema from a Neotropical monkey (Bain et al., 1982). In the Litomosoides lineage we included one species from a rodent and three from bats (Bain et al., 2003 and Guerrero et al., 2003); a species of the close genus Litomosa, was also included (Guerrero et al., 2002). In the Setaria lineage we included $S$. equina $(W$. pipientis negative, see Chirgwin et al., 2002) and two further species from cattle and roe deer. Parasites from amphibians (Ochoterenella sp., subfamily Waltonellinae), from reptiles (Foleyella furcata, subfamily Dirofilariinae) and from humans (L. loa, subfamily Dirofilariinae) were also examined. In addition, we included representatives of the Thelazioidea superfamily, whose branch is supposed to have diverged from the stem branch leading to filarial nematodes (Chabaud, 1974). In the species that were found positive for $W$. pipientis, 16S rDNA gene sequences were generated for the endosymbiont, for precise identification.

In parallel, we generated a new molecular data set for filarial nematodes, through sequencing of a $450 \mathrm{bp}$ portion of the small subunit ribosomal RNA gene of the mitochondrion (12S rDNA). This gene sequence was generated for 
Table 1. Species of filariae and related nematodes included in this study: collection details and the kind of samples used are given for those species for which PCR has been performed for Wolbachia pipientis screening and/or for DNA sequence generation

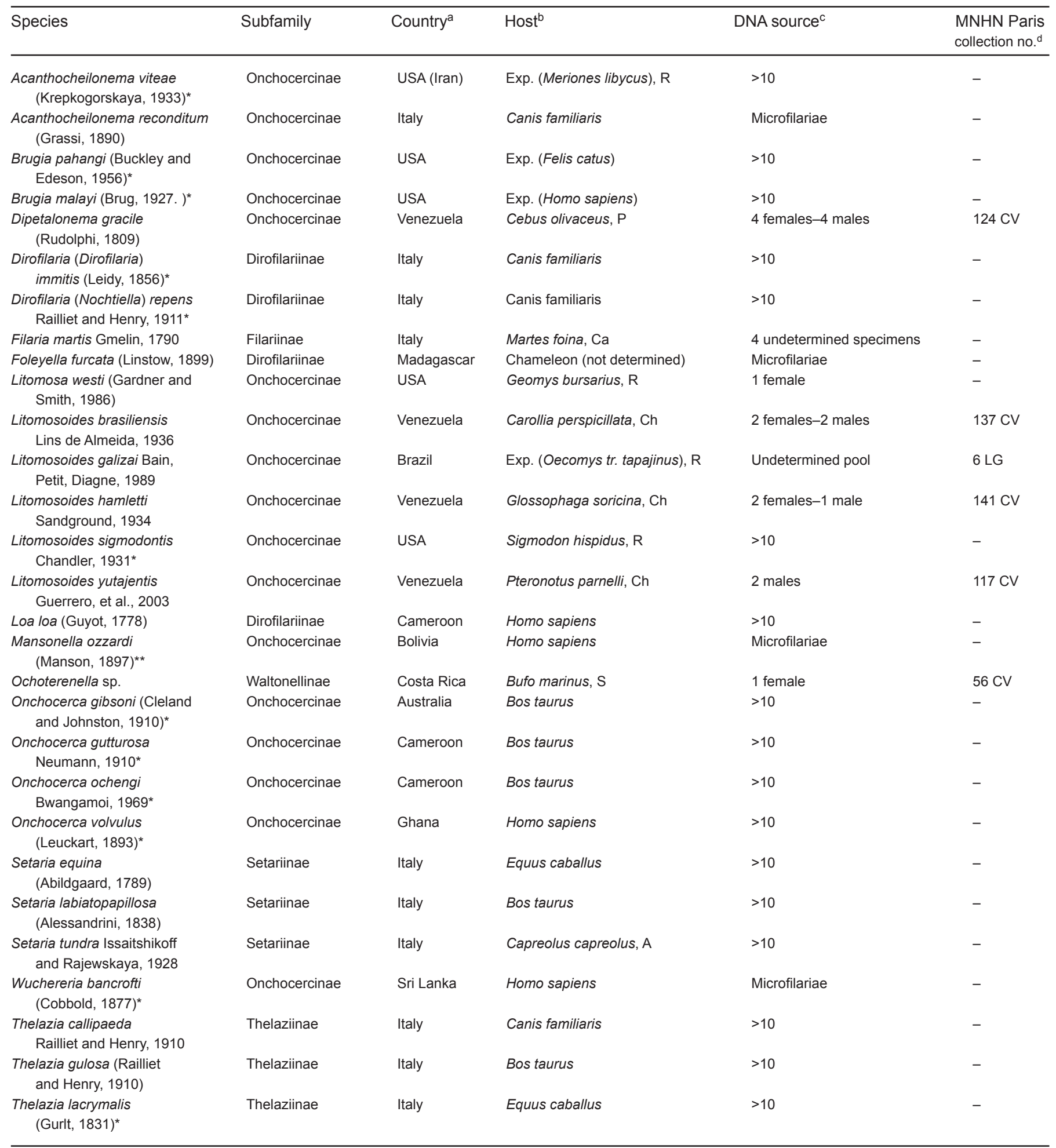

*Species included in Casiraghi et al. (2001b); **species included in Casiraghi et al. (2001a).

a Country, when different, between parentheses, specifies the original country of the filarial strain.

b The original host of the filarial strain is specified in parentheses; R, Rodentia; P, Primates; Ca, Carnivora; Ch, Chiroptera; S, Salientia; A, Artiodactyla.

c Where not specified, the samples examined were adult nematodes.

d Collection number is given for those species for which samples from the same collection used in this study are available at the Muse'um National d'Histoire Naturelle (MNHN Paris). 
a total of 28 filariae and related nematodes. In addition, the existing cytochrome oxidase I (COI) data set (formed by 12 sequences, see Casiraghi et al., 2001b) was updated with the generation of 16 further sequences of filariae and related nematodes. The $12 \mathrm{~S}$ rDNA and $\mathrm{COI}$ data sets were used in phylogenetic analysis, and the presence/absence of $W$. pipientis mapped on the trees generated.

\section{Materials and methods}

\subsection{Taxonomy of the specimens examined}

The taxonomy used in this paper follows Anderson and Bain, 1976; Chabaud and Bain, 1976; Bain et al., 1982; Anderson, 2000 and Guerrero et al., 2003. Representatives of the two families which compose the superfamily Filarioidea (order Spirurida) were examined, as well as the genus Filaria in the family Filariidae, and 13 genera in the Onchocercidae. These 13 genera are distributed into four of the eight subfamilies (Table 1; see also Figure 4): Setariinae: Setaria; Waltonellinae: Ochoterenella; Dirofilariinae: Foleyella, Dirofilaria, Loa; Onchocercinae: Dipetalonema, Acanthocheilonema, Litomosa, Litomosoides, Mansonella, Onchocerca, Brugia, Wuchereria. In addition, we included as an outgroup the genus Thelazia, which represents another branch of the order Spirurida: the superfamily Thelazioidea. This superfamily is thought to be closely related to the Filarioidea (Anderson, 2000). Its use as an outgroup for the Filarioidea is also justified by preliminary phylogenetic analyses of the order Spirurida based on ribosomal gene sequences (Casiraghi, unpublished observation).

\subsection{Spirurid species screened for W. pipientis}

A total of 16 spirurid nematode species were examined for the presence of $W$. pipientis. Onchocercidae: Setaria labiatopapillosa, S. equina, Setaria tundra, Ochoterenella sp., Acanthocheilonema reconditum, Dipetalonema gracile, F. furcata, Litomosa westi, Litomosoides brasiliensis, Litomosoides hamletti, Litomosoides galizai, Litomosoides yutajensis, and L. loa; Filariidae: Filaria martis; Thelaziidae: Thelazia gulosa and Thelazia callipaeda. Table 1 summarises data about hosts, collection places and material examined of the samples included in this study.

\subsection{Parasite species included in $12 S$ rDNA and COI gene sequencing}

DNA sequences from mitochondrial genes were generated for phylogenetic analyses (see below). 12S rDNA gene sequences were generated from 28 spirurid species (see Table 2). COI gene sequences were generated from the 16 species screened for $W$. pipientis (see Section 2.2). The $\mathrm{COI}$ sequences of the remaining 12 species have already been published (Casiraghi et al., 2001b).

\subsection{DNA preparation}

For all the parasite species examined, crude DNA preparations were obtained through proteinase-K treatment, according to Bandi et al. (1994). For A. reconditum, DNA from a pooled sample of microfilariae obtained through blood filtration was analyzed. For all the other species, DNA preparations from adult specimens were examined. When available, samples from three adult specimens of each species were treated separately with proteinase $\mathrm{K}$. In the case of Ochoterenella sp., L. yutajensis and L. westi only one female, two males and one female, respectively, were available for the investigation. All the DNA samples generated were screened for $W$. pipientis presence through PCR (see conditions below).

DNA preparations from filarial species harboring $W$. pipientis (Dirofilaria immitis and Brugia pahangi) and from a W. pipientis-infected strain of mosquitoes (Culex pipiens) were included in the screening as positive controls.

\subsection{PCR screening for $W$. pipientis: primers and $P C R$ conditions}

PCR screening for $W$. pipientis was conducted according to Casiraghi et al. (2001b), using general W. pipientis primers for 16S rDNA (99f and 994r; O'Neill et al., 1993) and for ftsZ (ftsZfl and ftsZrl; Werren et al., 1995). In addition, we used further general primers for 16S rDNA (16SWolbF and 16SWolbR3), and for ftsZ (ftsZUNIF and ftsZUNIR), originally designed on the basis of the $W$. pipientis sequences available for supergroups A-D (Casiraghi et al., 2001b), but whose target sites are also conserved in wolbachiae from supergroups $E$ and $F$ (Lo et al., 2002).

PCR was performed in a $20 \mu$ final volume under the following conditions: $1 \times$ buffer, $1.5 \mathrm{mM} \mathrm{MgCl}_{2}$ (Invitrogen $^{\mathrm{TM}}$ ), $0.2 \mathrm{mM}$ of each dNTP, $1 \mu \mathrm{M}$ of each primer, and $1 \mathrm{U}$ of Platinum ${ }^{\circledR}$ TaqPCRx DNA Polymerase (Invitrogen $\left.{ }^{\mathrm{TM}}\right)$. The thermal profile we used was: $94{ }^{\circ} \mathrm{C} 45 \mathrm{~s}, 52$ ${ }^{\circ} \mathrm{C} 45 \mathrm{~s}$, and $72{ }^{\circ} \mathrm{C} 90 \mathrm{~s}$ for 40 cycles.

In all the cases in which the specimens were negative under the above PCR conditions, a nested-PCR method was applied. The first PCR was performed using the general eubacterial primer 27F (Lane, 1991) combined with 16SWolbR3; PCR conditions were as above. One microlitre of the first PCR was diluted 1/10 in water, and then used as a template in a second PCR, performed using internal primers W-EF and W-ER (Werren and Windsor, 2000), whose target sites are conserved in supergroups E-F. PCR conditions with these primers were as described in Werren and Windsor (2000). On the negative specimens, we also performed PCR with primers $16 \mathrm{SWolbF}$ and 16SWolbR3 under different conditions. In particular, we tested the specimens at different $\mathrm{MgCl}_{2}$ concentrations (1.2, 1.5, 2.5 , and $4 \mathrm{mM})$, and under a gradient of annealing temperatures $\left(52 \pm 5^{\circ} \mathrm{C}\right)$. 
Table 2. List of the accession numbers of the sequences from filariae and related nematodes (12S rDNA and COI) and from their Wolbachia pipientis endosymbionts (16S rDNA) included in phylogenetic analysis; and presence/absence of W. pipientis as recorded in this and in previous studies on the basis of PCR examination

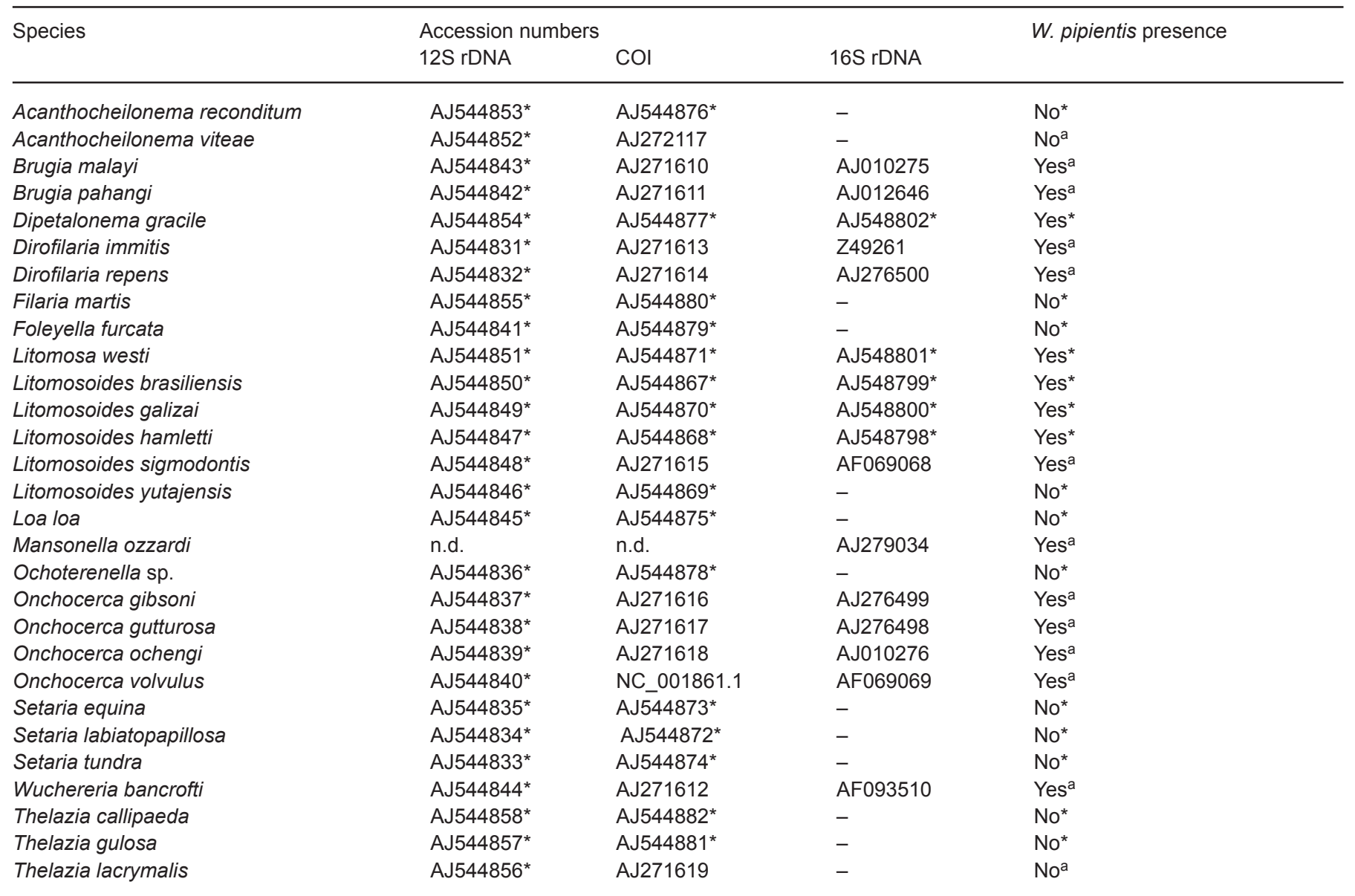

*Original results of the present study; n.d.: not done; dashes in the 16S rDNA column indicate that the sequences cannot be determined since these nematodes do not harbor W. pipientis.

a Results from previous studies (derived from Taylor and Hoerauf, 1999; Bandi et al., 2001).

From the newly detected positive species, a portion of the $16 S$ rDNA of $W$. pipientis was sequenced using primers 27F and 16SWolbR3. The amplifications obtained (about $1400 \mathrm{bp}$ ) were gel-purified (using the QIAquick® PCR Purification Kit, Qiagen) and directly sequenced using $A B I$ technology. The sequences obtained have been deposited in the EMBL Data Library (see accession numbers in Table 2).

\subsection{PCR on nematode mitochondrial genes: primer se- lection and design, PCR conditions}

$12 S$ rDNA amplifications and sequences were generated using a primer pair (12SF: 5'-GTT CCA GAA TAA TCG GCT A-3' and 12SR: 5'-ATT GAC GGA TG(AG) TTT GTA CC-3') designed on the basis of regions of $12 \mathrm{~S}$ rDNA conserved among the nematodes species Onchocerca volvulus, Ascaris suum and Caenorhabdites elegans, whose complete mitochondrial genome sequences are available in the databases (accession numbers: NC_001861.1; NC_001327.1; U80438/CELT19B4, respectively). The positions of $12 \mathrm{~S}$ rDNA primers on the complete mitochondrial genome of the filarial nematode O. volvulus are: 12SF: 7484-7502; 12SR: 7994-7975. PCR was performed in $20 \mu$ volumes under the conditions reported above, using the following thermal profile: $94{ }^{\circ} \mathrm{C} 45 \mathrm{~s}, 50{ }^{\circ} \mathrm{C} 45 \mathrm{~s}$, and $72{ }^{\circ} \mathrm{C} 90 \mathrm{~s}$ for 40 cycles. Under these conditions we obtained PCR products of the expected size (about $450 \mathrm{bp}$ ). The COI sequences were generated using the primer pair COlintF-COlintR under the PCR conditions described in Casiraghi et al. (2001b). The 12S rDNA and COI PCR products obtained were gel-purified (using the QIAquick $\circledast$ PCR Purification Kit, Qiagen) and directly sequenced using ABI technology. The sequences obtained have been deposited in the EMBL Data Library (for $12 \mathrm{~S}$ rDNA and COI accession numbers, see Table 2).

\subsection{Data analysis}

The obtained 125 rDNA sequences were aligned using the sequencer aligner tool available in the Ribo- 
somal Database Project (RDP; http://0-rdp.cme.msu. edu.library.unl.edu:80/html/), generating a 5228 bp long alignment, whose gaps were positioned according to the prealigned mitochondrial $12 \mathrm{~S}$ ribosomal genes of the nematodes $A$. suum and $C$. elegans present in RDP. Elimination of common gaps resulted in an alignment of 518 positions (accession no.: ALIGN_000516) on which the analyses were performed. The obtained $\mathrm{COI}$ gene sequences were aligned with the available sequences of O. volvulus (Keddie et al., 1998) and with those generated by Casiraghi et al. (2001b). This alignment was straightforward, with a very limited number of gaps.

Phylogenetic analyses were conducted using both distance matrix and character state methods. The distance matrix approach used was neighbor-joining (NJ), using Kimura 2-parameter or Jukes and Cantor corrections for the construction of distance matrices. The analyses were performed using TREECON 1.3B (Van De Peer and De Wachter, 1993). The character state methods used were maximum parsimony (MP), maximum likelihood (ML), and Bayesian inference of phylogeny (BI); the analyses were performed using PAUP* 4.0 b10 (Swofford, 1998), Tree-Puzzle 5.0 (Strimmer and Von Haeseler, 1996), and MrBayes 2.01 (Huelsenbeck and Ronquist, 2001). For MP, the tree was generated using the default heuristic search option in PAUP* $4.0 \mathrm{~b} 10$, with 5 random-addition sequence replicates. For $\mathrm{ML}$ and $\mathrm{BI}$, the appropriate models of sequence evolution for 12S rDNA and COI gene sequences were estimated via likelihood ratio test using Modeltest 3.06 (Posada and Crandall, 1998): the models selected were $H K Y+G$ for $12 \mathrm{~S}$ rDNA and $\mathrm{TrN}+\mathrm{I}+\mathrm{G}$ for $\mathrm{COI}$. For $\mathrm{ML}$, the tree was generated using Tree-Puzzle 5.0 with the $H K Y+G$ model of sequence evolution. In the analyses performed using MrBayes 2.01, for both $12 \mathrm{~S}$ rDNA and COI, a total of 100,000 trees were generated; and every 100 th tree was sampled. The first 500 trees were considered the burn in and discarded, and of the remaining 500 trees a $50 \%$ majority rule consensus tree was generated.

\section{Results}

\subsection{PCR screening for $W$. pipientis}

Out of the 16 species of spirurid nematodes screened for $W$. pipientis, the representatives of five species of the family Onchocercidae were found positive: $L$. hamletti, $L$. brasiliensis, L. galizai, L. westi and D. gracile (Table 2). The specimens representing the remaining 11 nematode species were PCR negative for $W$. pipientis, including a representative of the genus Litomosoides (L. yutajensis), the representative of the family Filariidae (F. martis), and the two representatives of the family Thelaziidae (T. gulosa and $T$. callipaeda). All these specimens were reproducibly negative under all the PCR conditions described.

\subsection{Phylogenetic analyses}

Figure 1 and Figure 2 show four examples of phylogenetic trees based on $12 S$ rDNA, obtained through four different approaches: NJ, MP (Figure $1 A$ and $B$ ); $M L$ and $\mathrm{BI}$ (Figure 2A and $\mathrm{B}$ ). The topologies shown in these trees are similar. In addition, the trees obtained using the NJ method under different corrections (Kimura 2-parameters and Jukes and Cantor) showed identical topologies. Six major groupings of species/genera are observed in most trees: (Onchocerca+Dirofilaria) $+F$. furcata; Litomosoides+Litomosa; Brugia+Wuchereria; Dipetalonema+Acanthocheilonema; Setaria spp.; Setaria+Ochoterenella. In all phylogenetic reconstructions, the genus Filaria is placed as a separate branch, representing the deepest branch of the superfamily Filariidae in three of the four trees. Phylogenetic reconstructions based on the COI gene were consistent with previously published results, based on a smaller data set (Casiraghi et al., 2001b), and with those based on $12 S$ rDNA, with recovery of the similar main groupings: Onchocerca+Dirofilaria; Litomosoides+Litomosa; Brugia+Wuchereria; Dipetalonema+Acanthocheilonema; Setaria spp.; deep branch position for the genus $\mathrm{Fi}$ laria (results not shown). Figure 3 shows the phylogenetic tree of $W$. pipientis, based on 16S rDNA gene sequences. The three positive species of the genus Litomosoides form a monophyletic grouping with $L$. sigmodontis, within the supergroup $D$ of $W$. pipientis. W. pipientis from $D$. gracile is placed as a deep branch of the C supergroup. W. pipientis from $L$. west $i$ is placed as the deepest branch of the genus Wolbachia.

\section{Discussion}

Our screening for $W$. pipientis in the superfamily Filarioidea revealed that $F$. martis, Ochoterenella sp., L. Ioa, F. furcata, L. yutajensis, A. reconditum and the three species examined for the genus Setaria do not harbor this bacterium. Outside the superfamily Filarioidea, the two species examined for the superfamily Thelazioidea were negative.

In the case of Setaria, we emphasise that different specimens have been tested for each species (see Table 1). Examinations conducted on several specimens of $S$. labiatopapillosa using electron microscopy and immunohistochemistry with antibodies against the Wolbachia surface protein also indicated an absence of $W$. pipientis or other intracellular bacteria (L. Sacchi and L.H. Kramer, unpublished results). Recently, microscopical examinations and PCR analysis have not revealed $W$. pipientis in S. equina (Chirgwin et al., 2002).

The absence of $W$. pipientis in $L$. loa reported in our work has also been recorded in other recent studies (Brouqui et al., 2001; Büttner et al., 2003 and Grobusch et al., 2003) and agrees with the results of previous 
(a) 0.05

100 Onchocerca volvulus

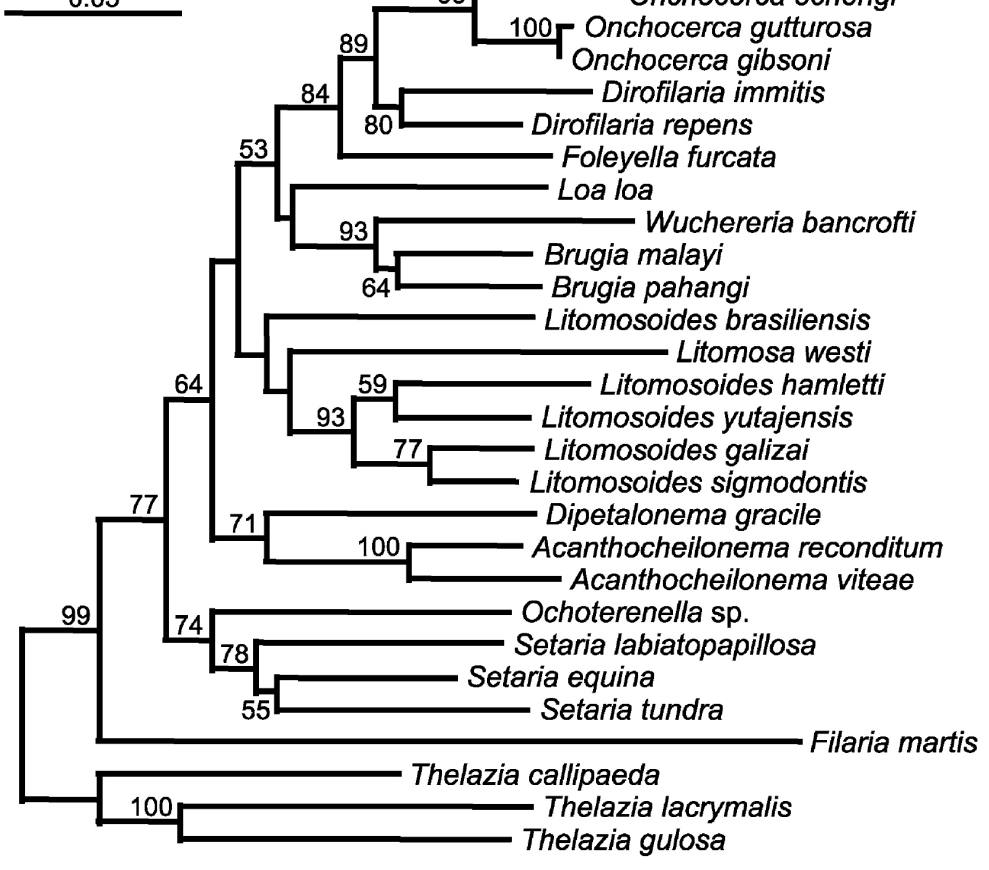

(b)

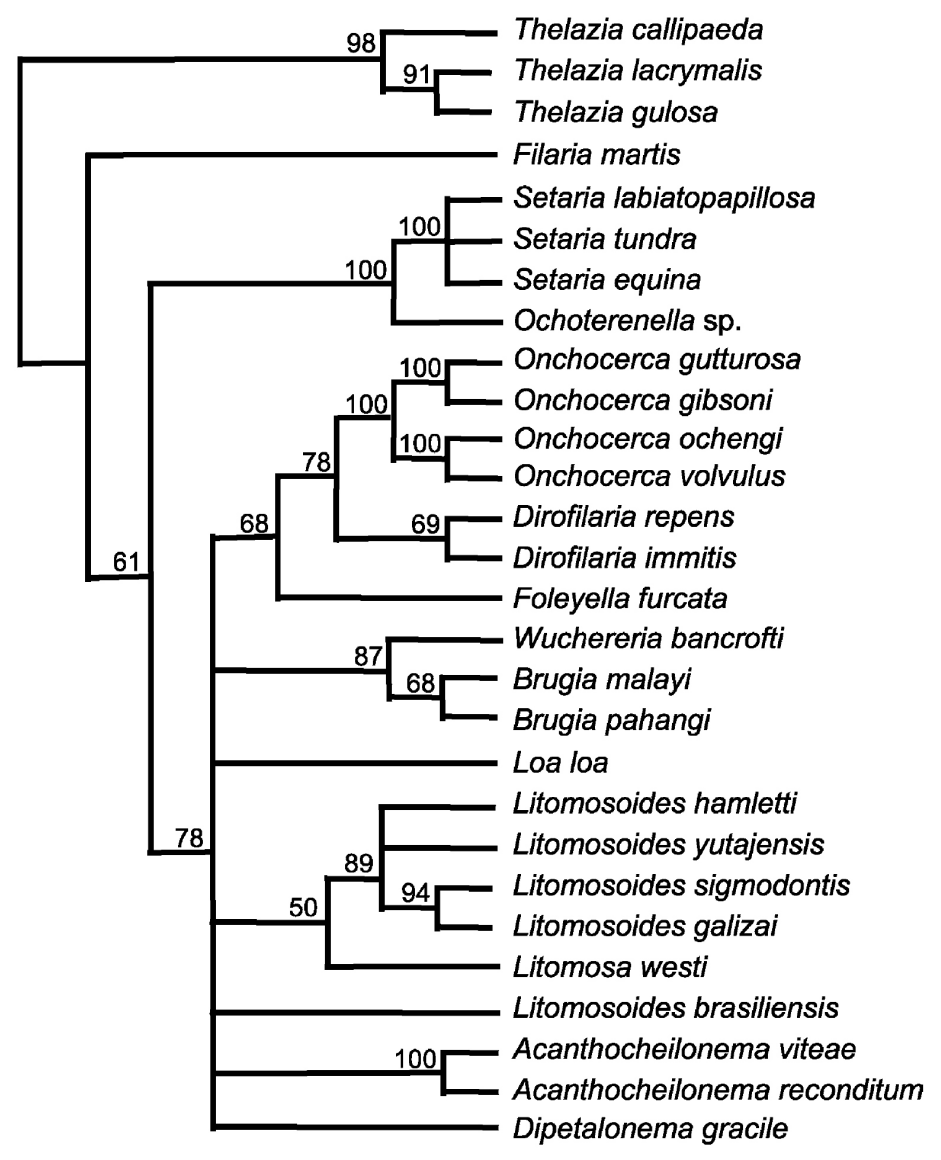

Figure 1. Phylogeny of filariae and related nematodes based on 12S rDNA gene sequences. Numbers at the nodes are the bootstrap confidence values after 100 replicates; bootstrap values below $50 \%$ are not shown. (a) Neighbor-joining tree obtained using the Kimura correction; the scale bar indicates the distance in substitutions per nucleotide; analysis performed using TREECON 1.3b. (b) Single most parsimonious topology generated using PAUP* 4.0 b10 under the default heuristic search option. The length of the tree is 892 steps. Consistency index after excluding uninformative characters is $0.45(\mathrm{RI}, 0.51 ; \mathrm{RC}, 0.23)$ 
(a)

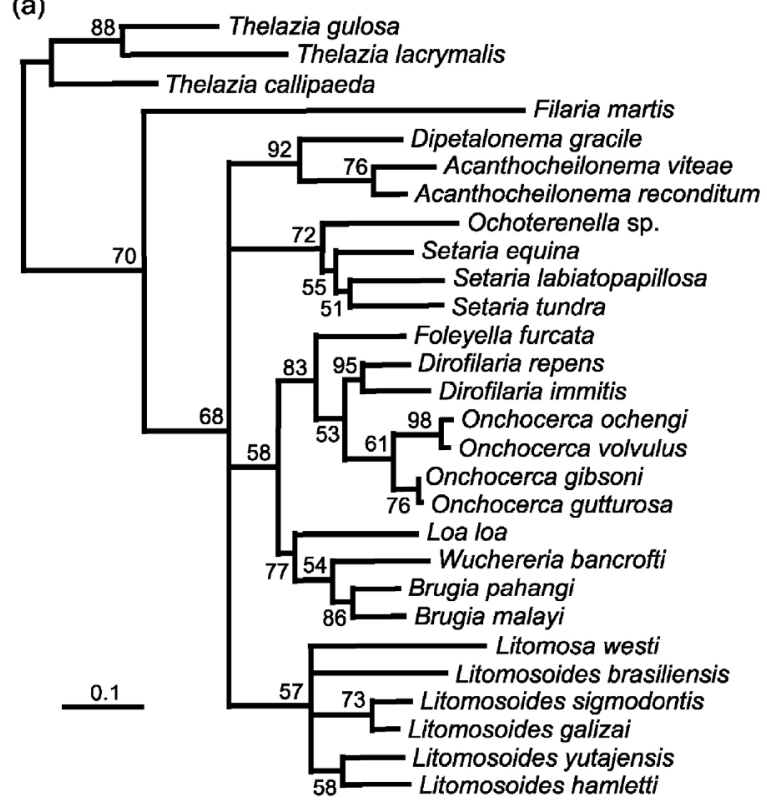

(b)

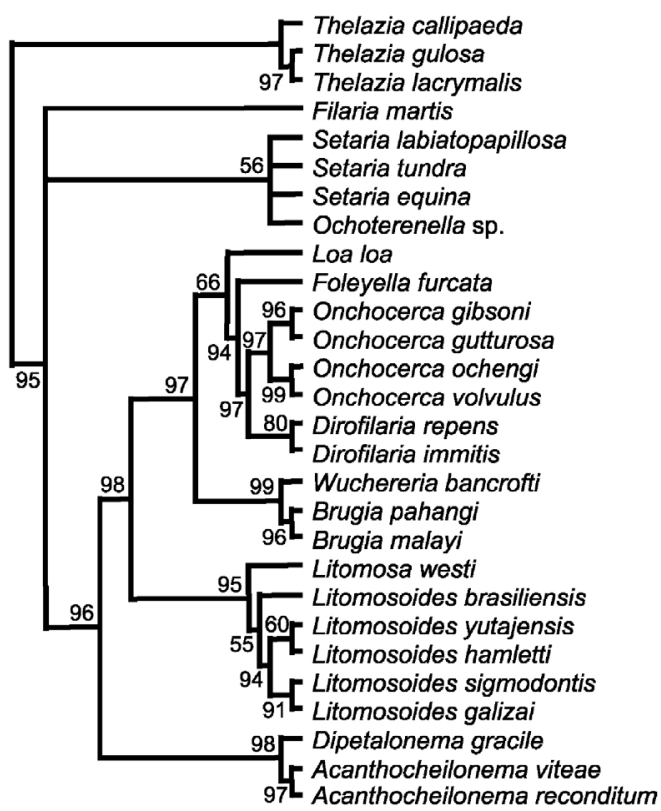

Figure 2. Phylogeny of filariae and related nematodes based on $12 \mathrm{~S}$ rDNA gene sequences. (a) Maximum likelihood tree generated using Tree-Puzzle 5.0. Values at the nodes represent the quartet puzzling support. The scale bar indicates the distances in substitutions per nucleotide. (b) Tree obtained by the Bayesian inference of phylogeny using MrBayes 2.01; numbers at the nodes are posterior probability values

investigations on the ultrastructure of this species (e.g. Franz et al., 1984). However, the side effects of filaricidal therapy in patients infected by $L$. loa (Gardon et al., 1997) might suggest that a bacterial component (i.e. $W$. pipientis) is implicated in these pathological outcomes. Some experimental evidence for the presence of $W$. pipientis in $L$. loa specimens have apparently been obtained (Taylor and Hoerauf, 2001), even though this evidence for positivity has not yet been published. The contrary evidence that samples of $L$. loa do not harbor $W$. pipientis is now reported in the three independent investigations that have already been published, and in our current study. This seems to suggest that components of these filarial nematodes are involved in the immunopathological side-effects of anti-loiasis chemotherapy.

In the genus Litomosoides four species out of five were positive for $W$. pipientis infection. The negative species, L. yutajensis, is a parasite of bats (see Table 1). Further analyses are however required to confirm this evidence, since our results are not based on many samples (see Table 1). If the absence of $W$. pipientis in L. yutajensis will be confirmed, this nematode will represent a new case of a species which does not harbor $W$. pipientis while being closely related with species which do. Indeed, there is already such an example in filarial nematodes: $O$. flexuosa does not harbor $W$. pipientis, while other species in the genus Onchocerca do (Plenge-Bönig et al., 1995 and Henkle-Dührsen et al., 1998). L. yutajensis could become an interesting model in the study of the relationship between W. pipientis and its nematode hosts, as well as in investigations on the immuno-pathological role of this bacterium in the course of filariasis. In this way, L. yutajensis could become a valid alternative to the use of $A$. viteae (which is negative for $W$. pipientis) as a sort of 'negative control' (e.g. see Hoerauf et al., 1999; McCall et al., 1999; Taylor et al., 2000 and Saint André et al., 2002), being more closely related to a filarial model which harbors $W$. pipientis $(L$. sigmodontis) than $A$. viteae (see Casiraghi et al., 2001b). Litomosoides species are thought to have evolved as parasites of bats in South America, and diversified in rodents only recently (about 3 millions years), when these migrated from North America during the Pliocene-Pleistocene; their passage into small marsupials is also believed to have occurred after the Pliocene-Pleistocene (Bain and Philipp, 1991 and Guerrero et al., 2002). It is hoped that screening of these species will reveal other Litomosoides species negative for $W$. pipientis, which could then be established in rodent laboratory hosts.

The presence/absence of $W$. pipientis in the other species of filariae examined is now discussed in the light of the results of our phylogenetic analyses. The different phylogenetic approaches used on 12S rDNA consistently recognised at least six major groupings of species/genera: (1) (Onchocerca+Dirofilaria) $+F$. furcata; (2) Litomosoides+Litomosa; (3) Brugia+Wuchereria; (4) Dipetalonema+Acanthocheilonema; (5) Setaria; and (6) Setaria+Ochoterenella. The genus Filaria was consistently placed as a deep branch. Setaria+Ochoterenella were placed quite consistently as deep branches within the representatives of the Onchocercidae family. Results of phylogenetic analysis on the $\mathrm{COI}$ gene (not shown) were in part consistent with those based on $12 \mathrm{~S}$ rDNA, with recovery of some of the above groupings (i.e. Onchocerca+Dirofilaria; Litomosoides+Litomosa; Brugia+Wuchereria; Dipetalonema+Acanthocheilonema; deep branch positioning of $F$. martis). As discussed in previous work (Casiraghi et al., 2001b), branch support in 


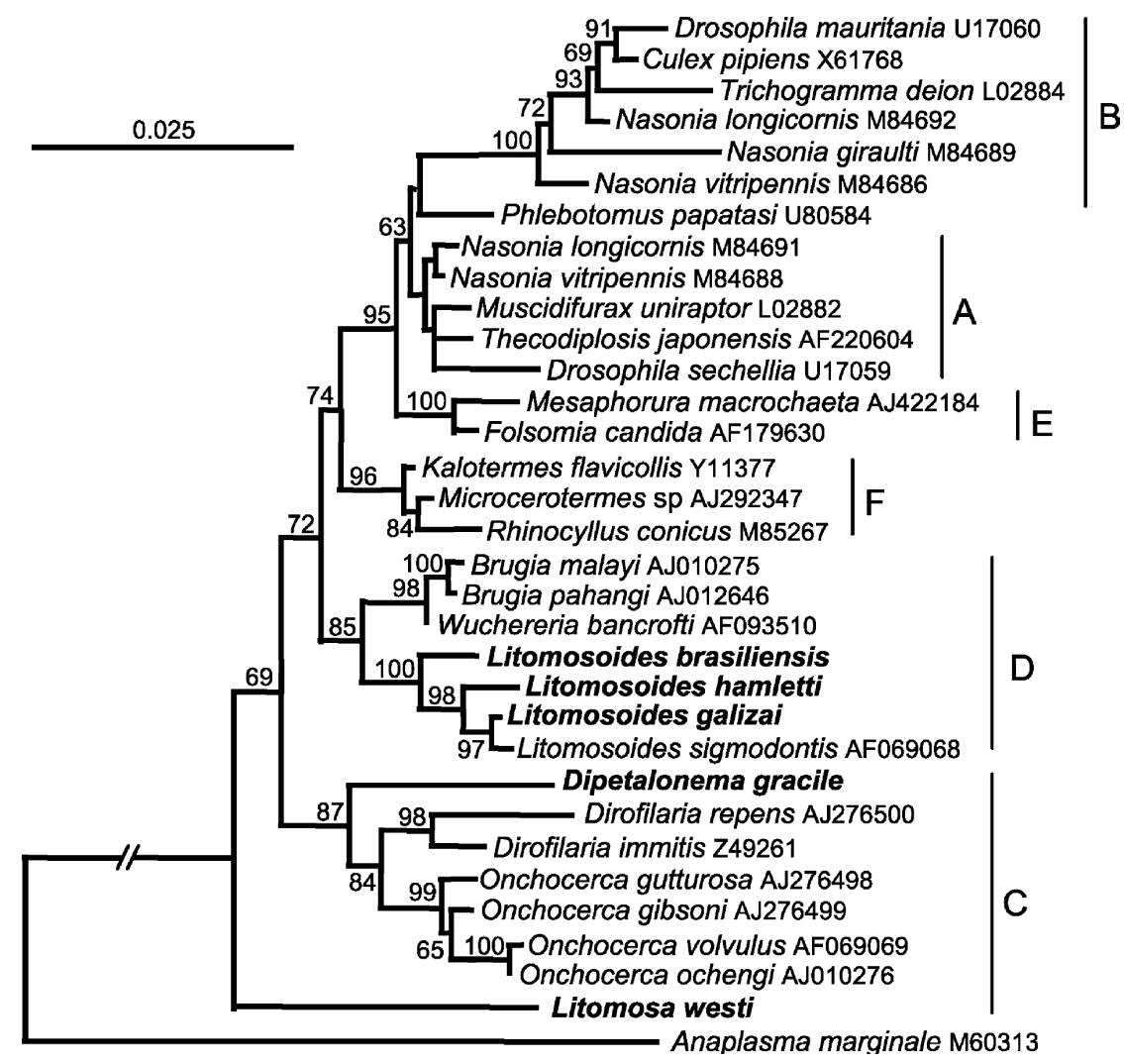

Figure 3. Phylogeny of Wolbachia pipientis based on 16S rDNA gene sequences. Names at the terminal nodes are those of the host species (with the exception of the outgroup, Anaplasma marginale). A-F are the names of the supergroups of $W$. pipientis according to Werren et al., 1995; Bandi et al., 1998; Vandekerckhove et al., 1999 and Lo et al., 2002. The tree has been obtained using the neighbor-joining method after Kimura correction, using TREECON 1.3b; numbers at the nodes are the bootstrap confidence values after 100 replicates; bootstrap values below $50 \%$ are not shown; the scale bar indicates the distance in substitutions per nucleotide; accession numbers are given for the sequences of $W$. pipientis from arthropods (the accession numbers of $W$. pipientis from nematodes are listed in Table 2); the five species in bold are the newly obtained sequences of $W$. pipientis from filarial nematodes.

trees based on the COI gene was generally lower when compared to the support observed in 12S rDNA trees, and the branching order of deep branches appeared less stable. Even though some aspects of the phylogeny of filarial nematodes have not been resolved by our analysis of $12 \mathrm{~S}$ rDNA and COI gene (i.e. the branching order of the major groupings listed above), the trees generated allow us to address some important issues regarding the evolution of the association between these nematodes and their $W$. pipientis endosymbionts. The grouping Dipetalonema+Acanthocheilonema was observed in most of the trees generated using both genes, with good bootstrap support. In addition, within this group we always observed a highly supported monophyletic group formed by $A$. viteae and $A$. reconditum. The genera Dipetalonema and Acanthocheilonema are thought to be closely related also on the basis of morphological characters (Anderson and Bain, 1976 and Bain et al., 1982).

The PCR evidence for the presence of $W$. pipientis in $D$. gracile is particularly interesting. The fact that $D$. gracile does harbor $W$. pipientis, while $A$. viteae and $A$. reconditum do not, suggests two alternative scenarios: (1) the common ancestor of Acanthocheilonema and Dipetalonema harbored $W$. pipientis and this bacterium has been lost during the evolution the lineage leading to $A$. viteae and $A$. reconditum; (2) the common ancestor of Acanthocheilonema and Dipetalonema did not harbor $W$. pipientis and this bacterium has been acquired during the evolution the lineage leading to $D$. gracile. These alternative possibilities will be discussed below, in the context of a more general scenario on the evolution of the association between $W$. pipientis and filariae. In any case, the sister group relationship of $A$. viteae and $A$. reconditum and the absence of $W$. pipientis in both species, weakens the hypothesis that this bacterium was lost in A. viteae during laboratory maintenance (see Section 1). As already discussed for $L$. yutajensis, D. gracile could become a useful species for comparisons with $A$. viteae in investigations on the biological and immunological role of $W$. pipientis.

Based on our current results, we have evidence for the presence of $W$. pipientis only in filarial nematodes of the family Onchocercidae. However, future studies should include further representatives of the family Filariidae. Within the Onchocercidae, groups of negative species were observed (i.e. Setaria spp.+Ochoterenella sp. and of the two species of Acanthocheilonema). There are thus filarial species which are negative for $W$. pipien- 
tis and appear to form monophyletic groups, while other negative species are more interspersed ( $L$. yutajensis, $L$. loa and $F$. furcata). It is interesting to note that $F$. furcata, a parasite of reptiles, was quite consistently placed as the sister group of Dirofilaria+Onchocerca, whose members are in most cases positive for $W$. pipientis.

The positioning of the wolbachiae of the five species of filariae that were found positive for $W$. pipientis in this study (L. brasiliensis, L. hamletti, L. galizai, L. westi and $D$. gracile) shows several interesting points. The wolbachiae harbored by the three species of the genus Litomosoides form a monophyletic group with that of $L$. sigmodontis. We emphasise that the phylogeny of the wolbachiae of Litomosoides spp.-all assigned to supergroup D (Lo et al., 2002)—is consistent with the phylogeny of the hosts (see trees in Figure 1 and Figure 2). These results are also consistent with the proposed phylogeny of the genus Litomosoides: the parasites of
Chiroptera (see Table 1) could represent a deep branch, while parasites from rodents could represent more recent lineages (Bain and Philipp, 1991 and Brant and Gardner, 2000). On the other hand, W. pipientis from $D$. gracile represents a deep branch within supergroup C. $W$. pipientis from $L$. westi was not assigned to any of the six supergroups of $W$. pipientis thus far described (Lo et al., 2002). Further analyses are required to investigate the positioning of this endosymbiont, particularly through the examination of other gene sequences.

In Figure 4 the presence/absence of $W$. pipientis is mapped on the possible phylogenetic tree of the filariae and related nematodes. This tree is based on the results of our phylogenetic analyses, and is partially congruent with the relationships inferred from other phylogenetic analyses (e.g. Xie et al., 1994) and with morphology-based classifications (Anderson and Bain, 1976 and Bain et al., 1982). The positioning of Mansonella spp. is

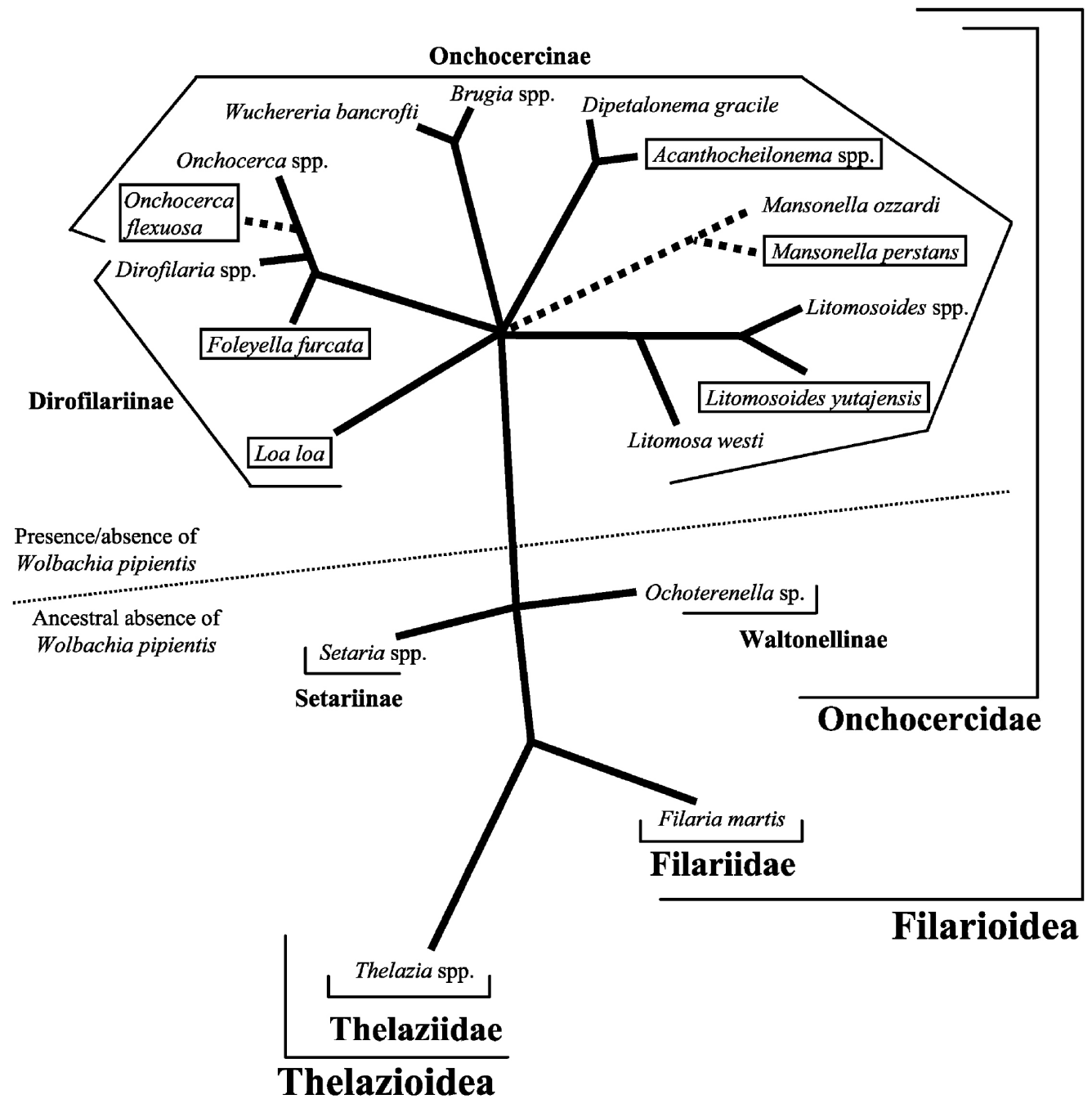

Figure 4. Hypothetical evolution of Wolbachia pipientis infection mapped on the phylogenetic tree of filariae and related nematodes. W. pipientis could have been ancestrally absent from the lineages leading to Thelazia spp., Filaria martis, Setaria spp. and Ochoterenella spp. W. pipientis could have been acquired on the lineage leading to the Onchocercidae family, and then lost along the lineages leading to Acanthocheilonema spp., Loa Ioa, O. flexuosa, Litomosoides yutajensis, Mansonella perstans (outlined in boxes). The positions of Mansonella spp. and O. flexuosa are based only on their taxonomic affiliations and are thus indicated by dashed lines (samples of these parasites were not available for generation of gene sequences). 
indicated with dashed lines, because it derives from previous phylogenetic analyses based on the $5 S$ rDNA gene spacer (Xie et al., 1994 and Casiraghi et al., 2001a). Since the branching order of the main lineages of the Onchocercinae and Dirofilariinae is still unresolved (see Section 3 and the discussion above), in Figure 4 these lineages are shown as stemming from an esafurcation. In summary, only those groupings of species of the Onchocercinae and Dirofilariinae which were reproducibly obtained in our analyses (and which have also been observed in other studies) are represented. The separation of the Thelaziidae (represented by Thelazia spp.) and the Filariidae ( $F$. martis) from the Onchocercidae (all the other species) is to be regarded as well established and widely accepted (Anderson, 2000). Inside the Onchocercidae, the separation of the Setarinae (Setaria spp.) and the Waltonellinae (Ochoterenella sp.) from the Onchocercinae and Dirofilariinae is also to be regarded as well established and widely accepted (Anderson, 2000).

Based on the tree in Figure 4, two different evolutionary scenarios can be proposed to explain the presence/ absence of $W$. pipientis in the different species of filarial nematodes. Absence of $W$. pipientis in the Filariidae, Setarinae and Waltonellinae could represent an ancestral condition. Acquisition of $W$. pipientis could have occurred: (1) once along the lineage leading to the Onchocercinae and Dirofilariinae and then there have been some losses in the branches leading to L. loa, F. furcata, Acanthocheilonema spp., O. flexuosa, L. yutajensis and M. perstans; or (2) several times along the Onchocercinae and Dirofilariinae subfamilies followed by some losses. At the moment it is not possible to decide which of these two hypotheses is the most favorable: the polytomy among the various lineages of the Onchocercinae and Dirofilariinae does not permit us to establish the status of the infection in the ancestors of the various lineages. However, scenario 2 would beg the following questions. Why in filarial nematodes have there been several independent acquisitions of $W$. pipientis, while there is no evidence for the presence of this bacterium in other nematodes? Why would wolbachiae acquired independently: (i) form monophyletic lineages (i.e. the wolbachiae of lymphatic filariae and Litomosoides spp. in supergroup D), (ii) be phylogenetically distant from the wolbachiae of arthropods, (iii) have similar genome sizes (Sun et al., 2001)? In conclusion, even though scenario 2 (multiple acquisition) cannot be excluded, we will concentrate our final discussion on scenario 1 (single acquisition, followed by losses; for a further discussion on the hypothesis of single acquisition of $W$. pipientis in filarial nematode ancestor, see Dedeine et al., 2003). In summary, scenario 1 involves the following: (a) some lineages are primitively not infected by $W$. pipientis (Thelazia spp., F. martis, Setaria spp., Ochoterenella sp.); (b) in other lineages $W$. pipientis infection has possibly been lost during evolution (O. flexuosa, F. furcata, L. Ioa, L. yutajensis, Acanthocheilonema spp., and M. perstans). From a phylogenetic perspective, the evidence for the loss of $W$. pipientis during evolution appears robust in the cases of the lineages leading to $O$. flexuosa and L. yutajensis (even though an explicit phylogentic analysis including $O$. flexuosa has never been published, and only two male specimens have been examined for L. yutajensis). For Acanthocheilonema spp., the sister group relationship with a positive species $(D$. gracile) begs the question of whether $W$. pipientis was acquired or lost along its lineage (see above); an answer to this question will require generation of a more robust phylogeny for filarial nematodes. A robust phylogenetic reconstruction is also required to address the issue of whether $W$. pipientis was acquired or lost in the lineages leading to $L$. loa and $M$. perstans. Point (b) opens interesting perspectives: if $W$. pipientis infection can really be lost during evolution, how stable is the association between these bacteria and their nematode hosts? Is it possible that the close relationship between $W$. pipientis and its nematode hosts shown in some recent papers (see Casiraghi et al., 2002) could be broken? Does the association between $W$. pipientis and the nematode host have the same 'strength' in all filarial species?

It is notable that the phylogeny of the family Onchocercidae based on $12 \mathrm{~S}$ rDNA and COI gene sequences is only in part congruent with the classification of filarial nematodes based on morphological and biological characters (Anderson and Bain, 1976). For example, the traditional assignment of the genera Dirofilaria and Onchocerca to the two subfamilies Dirofilariinae and Onchocercinae does not appear to be supported by our analysis, as well as by the results of Xie et al., 1994 and Casiraghi et al., 2001b. The sister group relationship of Onchocerca and Dirofilaria is however concordant with the similarity shown in the morphology of the infective stage of the representatives of these genera (Bain and Chabaud, 1986). Moreover, an important biological tract of the infective stages links these two genera: the first moult of these parasites in the vertebrate host $\left(\mathrm{J}_{3}\right.$ to $\left.\mathrm{J}_{4}\right)$ takes place early, within 2-3 days post-infection (Bain et al., 2002). Based on the results presented here and in the previous studies (Xie et al., 1994 and Casiraghi et al., 2001b) a taxonomical revision of the two subfamilies is required.

Finally, we emphasise that our paper presents for the first time molecular data sets for a representative sample of filarial species. These sets of data will in turn be useful for the molecular identification of juveniles or of fragments of adult nematodes. In fact, it is not uncommon to lose body parts useful for identification during collection of filariae from tissues.

\section{Note added in proof}

A further paper demonstrating the absence of Wolbachia in Loa loa is McGarry, H.F., Pfarr, K., Egerton, G., Hoerauf, A., Akue, J.P., Enyong, P., Wanji, S., Klager, S.L., Bianco, A.E., Beeching, N.J., Taylor, M.J. 2003. Evidence against Wolbachia symbiosis in Loa loa. Filaria J. 2:9. 


\section{Acknowledgements}

The authors would like to thank Nathan Lo and Dietrich Büttner for their criticisms and helpful reading of the manuscript. Claudio Genchi played a pivotal role in stimulating and encouraging this work. O. Bain, R. Guerrero and C. Martin collected most of the new material screened for the first time in this work ( $L$. brasiliensis, L. galizai, L. hamletti, L. yutajensis, Ochoterenella sp., D. gracile); S.L. Gardner collected the samples of $L$. westi; A. Franceschi collected the specimens of $S$. equina and $S$. labiatopapillosa. We would also like to thank for providing parasite material: J.W. McCall (B. malayi, B. pahangi, L. sigmodontis and $A$. viteae), L. Venco (D. immitis and $D$. repens), T. Bianco (O. ochengi, O. gutturosa and O. gibsoni), S. Novati (O. volvulus and L. loa), E. H. Karunanayake (W. bancrofti), D. Otranto (T. lacrimalis and T. gulosa), W. Bertazzolo (T. callipaeda), L. Rossi (S. tundra), S. Giannetto (A. reconditum), R. Lia (F. martis). We are grateful to M. Coluzzi for providing samples of Wolbachia-infected Culex pipiens. Special thanks go to Robin Gasser, for logistic assistance related with the shipment of $L$. galizai material. The work was supported by MIURCOFIN and CNRS-CONICIT grant nos. 10055 and 99000230. The authors wish to thank the excellent and thorough review of the manuscript.

\section{References}

Anderson, R.C., 2000. Nematode Parasites of VertebratesTheir Development and Transmission, CAB International, Wallingford.

Anderson, R.C. and Bain, O., 1976. Keys to genera of the order Spirurida. Part 3. Diplotriaenoidea, Aproctoidea and Filarioidea. In: Anderson, R.C., Chabaud, A.G. and Willmott, S., Editors, 1976. CIH Keys to the Nematode Parasites of Vertebrates 3, Commonwealth Agricultural Bureaux, Farnham Royal, pp. 59-116.

Bain, O., 1981. Filariids and their evolution. Evolution of $\mathrm{Hel}-$ minths (Workshop Proc., EMOP 3), Parasitology 82, pp. 161-174.

Bain, O., 2002. Evolutionary relationships among filarial nematodes. In: World Class Parasites, The Filaria. Kluwer, USA, 5, pp. 21-30.

Bain, O. and Chabaud, A.G., 1986. Atlas des larves infestantes de Filaires. Trop. Med. Parasit. 37, pp. 301-340.

Bain, O. and Philipp, M., 1991. Animal models in the study of the phenomenon of parasitism: filariae and other parasites. Ann. Parasit. Hum. Comp. 66 suppl. 1, pp. 64-68.

Bain, O., Baker, M. and Chabaud, A.G., 1982. Nouvelles données sur la lignée Dipetalonema. Ann. Parasitol. Hum. Comp. 57, pp. 593-620.

Bain, O., Babayan, S., Gomes, J. and Guerrero, R., 2002. First account on the larval biology of a Litomosoides filaria, from a bat. Parasitologia 44, pp. 89-92.

Bain, O., Guerrero, R., Rodrigues Ortiz, B., Babayan, S. and Jouvenet, N., 2003. Examination of type materials of Litomosoides spp. (Filarioidea: Onchocercidae), parasites from bats; taxonomic consequences. Parasite 10, pp. 211-218.

Balthazard, M., Chabaud, A.G., Mofidi, C. and Minou, A., 1953. Une nouvelle filaire de laboratoire. Ann. Parasitol. Hum. Comp. 28, pp. 387-391.

Bandi, C., Damiani, G., Magrassi, L., Gigolo, A., Fani, R. and
Sacchi, L., 1994. Flavobacteria as intracellular symbionts in cockroaches. Proc. R. Soc. London, B 257, pp. 43-48.

Bandi, C., Anderson, T.J.C., Genchi, C. and Blaxter, M.L., 1998. Phylogeny of Wolbachia in filarial nematodes. Proc. R. Soc. London, B 265, pp. 2407-2413.

Bandi, C., McCall, J.W., Genchi, C., Corona, S., Venco, L. and Sacchi, L., 1999. Effects of tetracycline on the filarial worm Brugia pahangi and Dirofilaria immitis and their bacterial endosymbionts Wolbachia. Int. J. Parasitol. 29, pp. 357-364.

Bandi, C., Dunn, A.M., Hurst, G.D. and Rigaud, T., 2001. Inherited microorganisms, sex-specific virulence and reproductive parasitism. Trends Parasitol. 17, pp. 88-94.

Blaxter, M., Daub, J., Guiliano, D., Parkinson, J. and Whitton, C., 2002. The Brugia malayi genome project: expressed sequence tags and gene discovery. Trans. R. Soc. Trop. Med. Hyg. 96, pp. 7-17.

Brant, S.V. and Gardner, S.L., 2000. Phylogeny of species of the genus Litomosoides (Nematoda: Onchocercidae): evidence of rampant host switching. J. Parasitol. 86, pp. 545-554.

Brouqui, P., Fournier, P.E. and Raoult, D., 2001. Doxycycline and eradication of microfilaremia in patients with loiasis. Emerg. Infect. Dis. 7, pp. 604-605.

Büttner, D.W., Wanji, S., Bazzocchi, C., Bain, O. and Fischer, P., 2003. Obligatory symbioticWolbachia endobacteria are absent from Loa loa. Filaria J. 2, p. 10.

Casiraghi, M., Favia, G., Cancrini, G., Bartoloni, A. and Bandi, C., 2001. Molecular identification of Wolbachia from the filarial nematode Mansonella ozzardi. Parasitol. Res. 87, pp. 417-420.

Casiraghi, M., Anderson, T.J.C., Bandi, C., Bazzocchi, C. and Genchi, C., 2001. A phylogenetic analysis of filarial nematodes: comparison with the phylogeny of Wolbachia endosymbionts. Parasitology 122, pp. 93-103.

Casiraghi, M., McCall, J.W., Simoncini, L., Kramer, L.H., Sacchi, L., Genchi, C., Werren, J.H. and Bandi, C., 2002. Tetracycline treatment and sex-ratio distortion: a role for Wolbachia in the moulting of filarial nematodes?. Int. J. Parasitol. 32, pp. 1457-1468.

Chabaud, A.G., 1974. Class nematoda-keys to subclasses, order and superfamilies. In: Anderson, R.C., Chabaud, A.G. and Willmott, S., Editors, 1974. CIH Keys to the Nematode Parasites of Vertebrates 3, Commonwealth Agricultural Bureaux, Farnham Royal, pp. 59-116.

Chabaud, A.G. and Bain, O., 1976. La lignée Dipetalonema. Nouvel essai de classification. Ann. Parasitol. Hum. Comp. 51, pp. 365-397.

Chabaud, A.G. and Bain, O., 1994. The evolutionary expansion of the Spirurida. Int. J. Parasitol. 24, pp. 1179-1201.

Chirgwin, S.R., Porthouse, K.H., Nowling, J.M. and Klei, T.R., 2002. The filarial endosymbiont Wolbachia sp. is absent from Setaria equina. J. Parasitol. 88, pp. 1248-1250.

Dedeine, F., Bandi, C., Boulétreau, M. and Kramer, L.H., 2003. Insights into Wolbachia obligatory symbiosis. In: Bourtzis, K. and Miller, T.M., Editors, 2003. Insect Symbiosis, CRC Press, Boca Raton, FL, pp. 267-282.

Franz, M., Melles, J. and Büttner, D.W., 1984. Electron microscope study of the body wall and the gut of adult Loa loa. $Z$. Parasitenkd. 70, pp. 525-536.

Gardon, J., Gardon-Wendel, N., Demanga-Ngangue, Kamgno, J., Chippaux, J.P. and Boussinesq, M., 1997. Serious reactions after mass treatment of onchocerciasis with ivermec- 
tin in an area endemic for Loa loa infection. Lancet 350, pp. 18-22.

Genchi, C., Sacchi, L., Bandi, C. and Venco, L., 1998. Preliminary results on the effect of tetracycline on the embriogenesis and symbiotic bacteria (Wolbachia) of Dirofilaria immitis. An update and discussion. Parassitologia 40, pp. 247-249.

Grobusch, M.P., Kombila, M., Autenrieth, I., Mehlhorn, H. and Kremsner, P.G., 2003. No evidence of Wolbachia endosymbiosis with Loa loa and Mansonella perstans. Parasitol. Res. 91, pp. 405-408.

Guerrero, R., Martin, C., Gardner, S.L. and Bain, O., 2002. New and known species of litomosoides (Nematoda: Filarioidea): important adult and larval characters and taxonomic changes. Comp. Parasitol. 69, pp. 177-195.

Guerrero, R., Martin, C. and Bain, O., 2003. Litomosoides yutajensis n. sp., first record of this filarial genus in a mormoopid bat. Parasite 10, pp. 219-225.

Henkle-Dührsen, K., Eckelt, V.H., Wildenburg, G., Blaxter, M. and Walter, R.D., 1998. Gene structure, activity and localization of a catalase from intracellular bacteria in Onchocerca volvulus. Mol. Biochem. Parasitol. 96, pp. 69-81.

Hoerauf, A., Nissen-Paehle, K., Schmetz, C., Henkle-Dürsen, K., Blaxter, M.L., Büttner, D.W., Gallin, M.Y., Al-Qaoud, K.M., Lucius, R. and Fleischer, B., 1999. Tetracycline therapy targets intracellular bacteria in the filarial nematode $\mathrm{Li}$ tomosoides sigmodontis and results in filarial infertility. J. Clin. Invest. 103, pp. 11-17.

Hoerauf, A., Volkmann, L., Hamelmann, C., Adjei, O., Autenrieth, I., Fleischer, B. and Büttner, D.W., 2000. Endosymbiotic bacteria in worms as target for a novel chemotherapy in filariasis. Lancet 355, pp. 1242-1243.

Huelsenbeck, J.P. and Ronquist, F., 2001. MrBayes: Bayesian inference of phylogeny. Bioinformatics 17, pp. 754-755.

Hurst, L.D. and Randerson, J.P., 2002. Parasitic sex puppeteers. Sci. Am., pp. 56-61.

Keddie, E.M., Higazi, T. and Unnasch, T.R., 1998. The mitochondrial genome of Onchocerca volvulus: sequence, structure and phylogenetic analysis. Mol. Biochem. Parasitol. 95, pp. 111-127.

Knight, J., 2001. Meet the Herod bug. Nature 412, pp. 12-14.

Kozek, W.J., 1977. Intracytoplasmic bacteria in Onchocerca volvulus. Am. J. Trop. Med. Hyg. 26, pp. 663-678.

Lane, D.J., 1991. 16S/23S rRNA sequencing. In: Stackebrandt, E. and Goodfellow, M., Editors, 1991. Nucleic Acid Techniques in Bacterial Systematics, Wiley, New York, pp. 115-175.

Lo, N., Casiraghi, M., Salati, E., Bazzocchi, C. and Bandi, C., 2002. How many Wolbachia supergroups exist?. Mol. Biol. Evol. 19, pp. 341-346.

McCall, J.W., Jun, J.J. and Bandi, C., 1999. Wolbachia and the antifilarial properties of tetracycline. An untold story. Ital. J. Zool. 66, pp. 7-10.

O'Neill, S.L., Gooding, R.H. and Aksoy, S., 1993. Phylogenetically distant symbiotic microorganisms reside in Glossina midgut and ovary tissues. Med. Vet. Entomol. 7, pp. 377-383.

Plenge-Bönig, A., Kromer, M. and Büttner, D.W., 1995. Light and electron microscopy studies on Onchocerca jakutensis and $O$. flexuosa of red deer show different host-parasite interactions. Parasitol. Res. 81, pp. 66-73.

Posada, D. and Crandall, K.A., 1998. Modeltest: testing the model of DNA substitution. Bioinformatics 14, pp. 817-818.

Saint André, A., Blackwell, N.M., Hall, L.R., Hoerauf, A., Brattig, N.W., Volkmann, L., Taylor, M.J., Ford, L., Hise, A.G., Lass, J.H., Diaconu, E. and Pearlman, E., 2002. The role of endosymbiotic Wolbachia bacteria in the pathogenesis of river blindness. Science 295, pp. 1892-1895.

Sironi, M., Bandi, C., Sacchi, L., Di Sacco, B., Damiani, G. and Genchi, C., 1995. Molecular evidence for a close relative of the arthropod endosymbiont Wolbachia in a filarial worm. Mol. Biochem. Parasitol. 74, pp. 223-227.

Stouthamer, R., Breeuwer, J.A.J. and Hurst, G.D., 1999. Wolbachia pipientis: microbial manipulator of arthropod reproduction. Annu. Rev. Microbiol. 53, pp. 71-102.

Strimmer, K. and Von Haeseler, A., 1996. Quartet puzzling: a quartet maximum likelihood method for reconstructing tree topologies. Mol. Biol. Evol. 13, pp. 964-969.

Sun, L.V., Foster, J.M., Tzertzinis, G., Ono, M., Bandi, C., Slatko, B. and O'Neill, S.L., 2001. Determination of Wolbachia genome size by pulse-field gel electrophoresis. J. Bacteriol. 183, pp. 2219-2225.

Swofford, D.L., 1998. PAUP, phylogenetic analysis using parsimony ("and other methods): version 4. Sinauer Associates, Sunderland, MA.

Taylor, M.J. and Hoerauf, A., 1999. Wolbachia bacteria of filarial nematodes. Parasitol. Today 15, pp. 437-442.

Taylor, M.J. and Hoerauf, A., 2001. A new approach to the treatment of filariasis. Curr. Opin. Infect. Dis. 14, pp. 727-731.

Taylor, M.J., Cross, H.F. and Bilo, K., 2000. Inflammatory responses induced by the filarial nematode Brugia malayi are mediated by lipopolysaccharide-like activity from endosymbiotic bacteria Wolbachia. J. Exp. Med. 191, pp. 1429-1436.

Van De Peer, Y. and De Wachter, R., 1993. TREECON: a software package for the construction and drawing of evolutionary trees. Comput. Appl. Biosci. 9, pp. 177-182.

Vandekerckhove, T.M.T., Watteyne, S., Willems, S., Swings, J.G., Mertens, J. and Gillis, M., 1999. Phylogenetic analysis of the 16S rDNA of the cytoplasmic bacterium Wolbachia from the novel host Folsomia candida (Hexapoda, Collembola) and its implications for the Wolbachia taxonomy. FEMS Microbiol. Lett. 180, pp. 279-286.

Xie, X., Bain, O. and Williams, S.A., 1994. Molecular phylogenetic studies on filarial parasites based on $5 S$ ribosomal spacer sequences. Parasite 1, pp. 141-151.

Werren, J.H., 1997. Biology of Wolbachia. Annu. Rev. Entomol. 42, pp. 587-609.

Werren, J.H. and Windsor, D.M., 2000. Wolbachia infection frequencies in insects: evidence of a global equilibrium?. Proc. R. Soc. London, B 267, pp. 1277-1285.

Werren, J.H., Zhang, W. and Guo, L.R., 1995. Evolution and phylogeny of Wolbachia: reproductive parasites of arthropods. Proc. R. Soc. Lond., B 261, pp. 55-71.

Zimmer, C., 2001. Wolbachia: a tale of sex and survival. Science 292, pp. 1093-1095. 